\title{
El debate por la legalización de las drogas
}

\section{The debate over drug legalization}

\author{
| Francisco de Asís Babín Vich
}

| Delegado del Gobierno para el Plan Nacional sobre Drogas

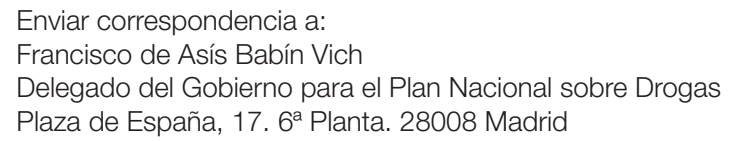

Plaza

\section{Resumen}

El debate sobre la legalización de las drogas surge con frecuencia en los medios de comunicación, pensando en una solución al tema del narcotráfico y otros problemas relacionados con su consumo. En España, el consumo privado e incluso la producción de pequeñas cantidades de determinadas plantas, cuyos principios activos tienen la consideración de drogas ilegales, siempre que sea claramente para el propio autoconsumo, no constituye una práctica penalizada por ninguna ley. Además al adicto se le considera un enfermo. No es asi siempre en los paises que han propugnado este debate, donde incluso existen en ocasiones leyes que persiguen al consumidor.

La población de nuestro pais, a través de su opinión expresada en las encuestas, prefiere incrementar las medidas preventivas, fomentar el tratamiento libremente asumido por las personas adictas y endurecer la represión del tráfico de drogas.

Por todo ello creemos que cuando se hable de "legalización" se debe ser escrupuloso con la semántica; no es lo mismo legalizar que despenalizar, no es lo mismo despenalizar el consumo que el tráfico y tampoco es lo mismo despenalizar el consumo privado que el público. Despenalizar el consumo privado es un hecho en nuestro pais. Más allá de esto, defendemos la estricta necesidad de analizar, desde una perspectiva científica, los hipotéticos beneficios a los que daría lugar la legalización. Desde luego, desde la perspectiva de la salud pública, es difícil encontrarlos. Creemos que la lógica que se ha seguido con el tabaco, incrementando las restricciones para su consumo, es la línea a seguir con cualquier sustancia adictiva.

\section{Abstract}

The debate over drug legalization appears frequently in the media as a potential solution to issues such as drug trafficking and other problems related to drug use. In Spain, private consumption or even the production of small quantities of certain plants, whose active ingredients are considered illegal drugs, if clearly for own consumption are not practices criminalized by any law. In addition, a drug addict is considered a person who is ill. Although it has not always been like that even in the countries that have called for this debate, where at times the law prosecutes consumers.

The population of our country, according to the views expressed in the opinion polls, prefer to increase preventive measures, foster the treatment freely assumed by drug addicts and make stricter the repression on drug trafficking.

Therefore, when speaking of "legalization" we should be scrupulous with the semantics; legalize and decriminalize are not the same, it is not the same decriminalize consumption than decriminalize trafficking, neither is the same decriminalize private consumption than public consumption. Decriminalize private consumption is a fact in our country. Beyond this, we advocate for the strict need to analyze from a scientific perspective the hypothetical benefits that would result from drug legalization. Certainly, from the public health perspective, they are hard to find. We believe that the same logic applied to tobacco, increasing the restrictions on its use, is the path to follow with any addictive substance.

Key Words: Spain, drug legalization, illegal drugs, tobacco. 
$\mathrm{D}$ esde hace unos años, son cada vez más frecuentes las intervenciones de líderes políticos y expresidentes de diversos países, que junto con los grupos procannábicos abogan por la generalización de un debate a favor de la "legalización de las drogas". La última Cumbre de las Américas ha establecido así mismo, la idoneidad de abrir un debate sobre la situación de la lucha contra el narcotráfico y la búsqueda de alternativas a la política actual de control de la oferta y de la demanda de dichas sustancias. Lógicamente los medios de comunicación se han hecho eco de esta iniciativa que será dirigida por la Comisión Interamericana Contra el Abuso de Drogas (CICAD) una de las divisiones de la Organización de Estados Americanos (OEA).

La prohibición mediante listas cerradas de la producción, recolección y distribución de determinadas plantas como origen de diversas drogas, es una iniciativa respaldada por la mayoría de los gobiernos que han suscrito las tres convenciones internacionales existentes sobre la materia; la del opio en 1912 y las dos más modernas impulsadas por la Organización de las Naciones Unidas (ONU). En un debate como el que se pretende, la información a la ciudadanía llegará, como siempre, a través de los medios de comunicación, siendo esencial, para que dicha información sea fidedigna, que se estructure sobre un lenguaje preciso, exento de generalizaciones que más bien desinforman. Así por ejemplo, no es lo mismo legalizar que despenalizar, no es lo mismo despenalizar el consumo que el tráfico y tampoco es lo mismo despenalizar el consumo privado que el público.

En España, el consumo privado e incluso la producción de pequeñas cantidades de determinadas plantas, cuyos principios activos tienen la consideración de drogas ilegales, siempre que sea claramente para el propio autoconsumo, no constituye una práctica penalizada por ninguna ley. No así en la mayoría de los países que han propugnado este debate, donde la preocupación siempre ha estado centrada en el control de la oferta a través de la represión del tráfico de drogas, pero donde además se han mantenido y aún se mantienen, leyes y/o actitudes de persecución contra los consumidores que lógicamente existen, en todos los países en los que las drogas se producen, discurren o se distribuyen hacia los usuarios finales.

En la base de esta diferenciación está la consideración del adicto como un enfermo en nuestro país, atendiendo a la evidencia científica disponible, frente a la consideración de delincuente que tiene en la mayor parte de los países del globo terráqueo. Es por ello que apelamos a que, para mayor claridad a la hora de fijar la posición de cada cual, cuando se hable de "legalización" se sea escrupuloso con la semántica; pues no es lo mismo reconocer la existencia de la enfermedad adictiva y proceder en consecuencia, que aceptar que la producción, recolección, distribución y venta de las drogas, pasen a constituir un mercado libre, auspiciado por gobiernos o "empresas" autorizadas para ello.

Nuestro país ha opinado a través de las encuestas que realiza la Delegación del Gobierno para el Plan Nacional Sobre Drogas. En ellas se concluye que la población prefiere incrementar las medidas preventivas, fomentar el tratamiento libremente asumido por las personas adictas y endurecer la represión del tráfico de drogas, que "favorecer" el mercado de la droga convirtiéndolo en un mercado libre, posición que defiende una minoría de nuestros conciudadanos.

Algunos de los argumentos utilizados por quienes propugnan un mercado libre (ya sea del cannabis o de todas las drogas), se estructuran ante hipotéticos beneficios como el incremento de la recaudación estatal vía impuestos, una supuesta oportunidad de acabar con los mercados ilegales, o el beneficio terapéutico que algunas de estas sustancias podrian aportar.

¿Hay alguna evidencia de que la liberalización del mercado disminuiría el drama?, evidentemente no, pues es un hecho incontrovertible que las drogas más consumidas son legales (tabaco y alcohol, junto con ansiolíticos y otros fármacos). ¿Acaso alguien piensa que las mafias desaparecerán por la legalización?, evidentemente no, porque no es la droga su único negocio; estos cárteles están en la base de las redes de trata de personas, en el comercio ilegal de minerales y piedras preciosas, en el de armas, etc. Además tenemos el caso del tabaco donde su legalidad no impide que siga existiendo un floreciente contrabando. ¿Acaso se puede sostener que un hipotético beneficio por la tributación de un negocio legal debiera justificar el cambio de actitud?, ciertamente no, porque supuesto que hiciéramos abstracción de la evidente falta de ética que comporta dicha posibilidad, el gasto asociado al aumento del consumo esperable haría mucho más gravosa esta vía al tener que acometer el coste derivado de su tratamiento a nivel individual y social. Y, por encima de todo, tenemos como sociedad un deber de proteger a los adolescentes y jóvenes. ¿Puede alguien garantizar que cualquier medida de legalización, por controlada que sea, no va a aumentar las posibilidades de acceso de los menores de edad a estas sustancias?, mas bien los datos disponibles indican lo contrario.

En cuanto al supuesto beneficio terapéutico del cannabis, tan defendido por las asociaciones cannábicas, es cierto que algunas sustancias presentes en el cannabis pueden tener propiedades que mejoran ciertas patologías, bien relacionadas con la espasticidad muscular, bien relacionadas con el dolor, o bien con la sintomatología derivada de los tratamientos oncológicos fundamentalmente. Pero es igualmente cierto, que sólo en unos pocos casos la administración de THC se ha mostrado más eficaz que otros tratamientos ya existentes para mejorar el estado del paciente y que para dichos casos ya existen productos farmacéuticos que contienen el THC como principio activo y que permiten su uso en el marco de la relación médico-paciente. En definitiva, la sociedad no ha dado la espalda a las posibilidades terapéuticas de los cannabinoides, siendo nuestro país uno de los avanzados en este tipo de investigación. La clave de todo esto no es si fumar cannabis es terapéutico, sino investigar la mejor forma y dosificación, en que determinados cannabinoides son eficaces frente a determinados problemas. Ello es exactamente el protocolo que se sigue y se debe seguir en la investigación de cualquier medicamento. Es obvio que si se hubiera probado que el balance riesgo/ efectividad fuese positivo para otras patologías o síntomas, el medicamento se licenciaría para otras indicaciones, pues nada interesaría más a la industria farmacéutica que conseguir ampliar su ámbito de aplicación. 
En todo caso, el uso autoadministrado del cannabis, con finalidad terapéutica, a través de la liberalización del mercado, estaría dentro del concepto de automedicación que siempre hemos rechazado desde la práctica clínica y de salud pública por los riesgos que conlleva.

Tampoco existe el supuesto vacío legal que algunos aducen como motivo para desarrollar legislaciones "ad hoc" en territorios concretos. En esa línea hay que recordar que la Ley Orgánica 1/2002, de 22 de marzo, reguladora del Derecho de Asociación, establece que la inscripción en el Registro de Asociaciones, de las asociaciones reguladas en esa normativa, se entiende realizada a los únicos efectos de publicidad. No se puede aducir por tanto que la inscripción supone de facto el derecho a cultivar, recolectar y distribuir cannabis como algunos pretenden, dando lugar a un supuesto "vacío legal" por la falta de concreción de la cantidad que puede ser cultivada, recolectada y distribuida, simplemente porque nuestro ordenamiento jurídico contempla como ilícito penal, siempre y en cualquier cantidad, el compendio de dichas actividades.

Tampoco se puede aducir que el cultivo, recolección y distribución de cannabis, auspiciado por los clubes esté dentro del concepto de "autoconsumo" ni del de "consumo compartido", avalados por la jurisprudencia del Tribunal Supremo, pues como claramente ha quedado definido, sólo se puede considerar como tal, el que cumple todas y cada una de las siguientes condiciones: que los consumidores sean adictos; que el consumo se efectúe en lugar cerrado sin que puedan inmiscuirse terceras personas o que haya riesgo de difusión o de visión por los efectos perjudiciales que dicho consumo conlleva; que la cantidad de droga sea insignificante; que la coparticipación consumista venga referida a un pequeño núcleo de drogodependientes como acto esporádico e íntimo sin trascendencia social; que los consumidores sean personas ciertas y determinadas, como modo de verificar todo lo anterior y que ha de tratarse de un consumo inmediato de las sustancias adquiridas. Todo ello explica el por qué las asociaciones inscritas, son perseguidas en cuanto comienzan su actividad de cultivo y distribución, a la que se aplicaría el código penal, al constituir un ilícito penal perfectamente tipificado, como lo es también por cierto cualquier actividad que haga apología del consumo de drogas.

La solución al debate se encuentra con más credibilidad, en la lucha contra la pobreza que lleva a poblaciones indígenas a cultivar estas plantas como modo de subsistencia. En la cooperación internacional, no sólo para el desarrollo, sino también en la lucha contra el narcotráfico con intercambios de información entre países más precoces y efectivos, incluyendo el movimiento de sustancias químicas utilizadas en la elaboración de las drogas para su venta. En la consideración del adicto como paciente antes que como delincuente.

Nuestro país, contribuye a través de su reconocida experiencia y liderazgo en estos debates. Así, en el proyecto de Cooperación en Políticas de Drogas entre América Latina y la Unión Europea (COPOLAD) que lideramos, se está elaborando, con el concurso de todos los países participantes, una síntesis de la evidencia, como resumen para la toma de decisiones aplicables en los paises de América Latina, para la mejora de las políticas de drogas.
En un mundo como el que nos ha tocado vivir, es imposible que podamos sustraernos a un debate como el que acontece alrededor de las drogas y su control. Participemos por tanto en él, teniendo claros los objetivos y sabiendo que este debate no debe estar imbuido de cuestiones ideológicas, de "falsas premisas" y de "grandes soluciones". Estas grandes soluciones directamente no existen. Quizás la hoja de ruta a tener en cuenta es la seguida con el tabaco. A partir del conocimiento de los problemas ligados a su consumo, la sociedad ha tomado conciencia de lo que ocurría. A partir de aquí se han ido tomando decisiones cada vez más restrictivas, contando además con el beneplácito y la aceptación de la sociedad e incluso de los propios fumadores. Es decir, cada vez se ponen más cortapisas al fumador y esto está funcionando. ¿Por qué iba a ser distinto el procedimiento a seguir con otras drogas?

El único enfoque posible, desde una perspectiva responsable, debe ser el de la salud comunitaria y en el caso de nuestro país, la ejecución de la Estrategia Nacional sobre Drogas 20092016, de la que nos hemos dotado con un importante consenso y cuya primera línea estratégica pretende promover una conciencia social sobre la importancia del problema de la droga, basada en la evidencia disponible y alejada de otros intereses. 
